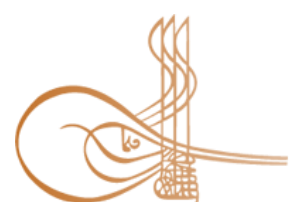

www.turkishstudies.net/language

\section{Turkish Studies - Language and Literature}

eISSN: 2667-5641

Research Article / Araștırma Makalesi

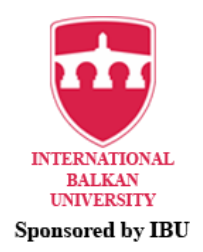

Sponsored by IBU

\title{
Mîhâîl Nu'ayme'nin Saâdetu'l-Beyk Adlı Kısa Öyküsünün Türkçe Çevirilerinin Karşılaştırmalı Çözümleme Yöntemiyle İncelenmesi
}

\author{
Comparative Analysis of The Turkish Translations of Mikhail Nuayma's Short Story Named \\ "Saâdetu'l-Beyk"
}

\author{
Gürkan Dağbaşı ${ }^{*}$ - Kübra Ayşe Ayhan**
}

\begin{abstract}
Translation is not only an activity between different languages, but also intercultural. In the translation process, the translator should constantly consider the loyalty to the source text and the expectations of the target language reader according to the situation. The purpose of the translator of literature is to produce an equivalent text to the source text in terms of its linguistic function. However, the equivalence here is achieved not only by identification at the linguistic sign or content level, but by preserving the communicative function of an expression in a different language and culture. The translation text should have the language and culture norms of the source text as necessary. Translation criticism includes comparative analysis of source text and target text. In this analysis, besides the source and target texts, the systems to which they belong must also be considered. The aim of the comparative analysis is to identify the factors that affect the target text during the translation action and to investigate the causes of deviations from the source text. Story type has an important place among the translations from Arabic literature to our language. Mikhail Nuayma, who is accepted as the Maupassant of the Arabs in the field of story, is considered as one of the most important representatives of modern Arabic Literature with his works in various genres such as novels, stories, theater, articles, criticism, poetry and biography. In this study, the translations of the sections selected from the short story named "Saâdetu'l-Beyk" (سعادة البيك) of Mikhail Nuayma, which was translated into Turkish by Erdinç Doğru, Gürkan Dağbaşı and Kenan Demirayak, were examined with comparative translation method. As a result of this review, based on the context of competence and acceptability, some conclusions have been reached regarding the source or target text orientation of the translations, differences between translator decisions, translation approaches adopted by translators and the equivalence of translations to the source text in linguistic, syntactic and semantic terms.
\end{abstract}

\footnotetext{
* Doç. Dr., Ankara Hacı Bayram Veli Üniversitesi, Yabancı Diller Yüksekokulu, Yabancı Diller Bölümü Assoc. Prof. Dr. Ankara Haci Bayram Veli University, Academy of Foreign Languages, Department of Foreign Language ORCID 0000-0002-2050-9213

gurkan.dagbasi@hbv.edu.tr

** Yüksek Lisans Öğrencisi, Ankara Hacı Bayram Veli Üniversitesi, Lisanüstü Eğitim Enstitüsü, Çeviri ve Kültürel Çalı̧̧malar Programı

MA Student, Ankara Haci Bayram Veli University, Institute of Graduate Programs, Program of Translation and Culturel Studies

ORCID 0000-0001-8388-8268

kubraayseayhan@gmail.com

Cite as/ Atıf: Dağbaşı, G. \& Ayhan, K.A. (2020). Mîhâil Nu'ayme'nin Saâdetu'l-Beyk adlı kısa öyküsünün Türkçe çevirilerinin karşılaştırmalı çözümleme yöntemiyle incelenmesi. Turkish Studies - Language, 15(3), 1131-1148. https://dx.doi.org/10.47845/TurkishStudies.44150

Received/Geliș: 10 June/Haziran 2020

Accepted/Kabul: 15 September/Eylül 2020

Copyright $($ INTAC LTD, Turkey

Checked by plagiarism software

Published/Yayın: 30 September/Eylül 2020

CC BY-NC 4.0
} 
Structured Abstract: Translation is a linguistic activity that enables intercultural communication and allows people who speak different languages to be aware of each other. According to Stolze, each translation is a journey to a different time, place or culture (Şanverdi, 2019: 241). In our world, with the development of science and technology, the concept of translation maintains its importance with all the problems it encounters as an integral part of communication both at the language and language level (Aktaş, 1996). It will be conceptually shallow to formulate the phenomenon of translation as a process that is applied between two languages. Cultural, political, social, and historical values should not be ignored while putting forward the translation product. Each society is shaped according to certain norms and these norms include the value judgments of that society. The translator is to make decisions that do not harm the value judgments of both communities, and in this context, should make a fair translation by demonstrating its neutrality and considering the social value system (Ulusahin, 2018: 146).

The fact that the subject of what is to be criticized in translation criticism can change according to the theoretical approach adopted inevitably creates a confusion in translation criticism discourses. The basis of this turmoil is the relativity of many concepts such as equivalence, suitability, functionality, resource and goal orientation. However, with the increasing number of different studies and goal-oriented theories in the field of translation criticism on the theoretical level and in the field of application, today, translation criticism has moved away from being a transfer of only subjective tastes, intuitions and tastes, and has experienced an orientation towards objectivity and science. (Aksoy, 2001: 40; Yücel, 2007: 41). In order to be able to make translation criticism as set forth in translation studies, it is necessary to determine the limits and requirements of this effort very carefully. First and foremost, the critic must know the translation process very well. The critic is expected to know what the translation process requires, what the task of the translator is, how the translation problems can be overcome, and be aware of the tradition of translation in the target language and culture. Additionally, the critic is expected to be able to analyse the source text in a systematic way by emphasizing its language, culture, message and literary features. Furthermore, the critic is to be able to perform the same process on the translation text. He/she is to be able to compare the data resulting from these processes and evaluate them objectively and subjectively within the framework of translation theory and translationliterary traditions (Aksoy, 2001: 2).

The short story genre first appeared in the 19th century. It was the American writer Edgar Allan Poe who first discovered this genre. The short story genre has spread all over the world, thanks to the skilful litterateurs who produced similar works after Poe (Tasa, 2006: 133).

"Saâdetu'l-Beyk" is considered as one of the most beautiful stories of the story collection named "Kâne mâ Kâne" by Mîhâîl Nu'ayme, one of the leading names in "Migration Literature", which constitutes an important stage of Modern Arabic Literature (Koç 2013: 50-53). In Turkish, that work was translated and titled as "Bey Hazretleri" in the translation selection titled "Kısır" by Kenan Demirayak (2000); It has also been translated by Erdinç Doğru (2002) and titled as "Beyefendi" in the translation selection named "Onuncu Günde Kaplanlar". The translation of Gürkan Dağbaşı (2017) was published with the title of "Bey Hazretleri" in the translation selection titled "Arabic Short Stories with Turkish Translations". In this study, some sections selected from Mîhâ îl Nu 'ayme's short story named "Saâdetu'l-Beyk" (سعادة البيك), which were translated by Erdinç Doğru, Gürkan Dağbaşı and Kenan Demirayak were analysed with comparative translation method. As a result of this analysis, some conclusions were reached regarding the source or target text focus of translations, differences between translator decisions, translation approaches adopted by translators and the measure of equivalence of translations to source text in terms of linguistic, syntactic and semantic aspects. As a result of examining the sections selected from the source and target texts, an evaluation about the preferences of translators and the approaches they used can be made. When all three translations are examined, it is recognized that all translators provided semantic equivalence. Of course, they did this with different preferences for their own purposes. The differences between the preferences of translators were intensely reflected in the transfer of idioms. All three translators mostly focused on finding the equivalence of the idioms in the target language during the translation process. Translators sometimes preferred a translation which was close to the culture of source text and sometimes to the target text. However, by looking at the approaches they preferred, it can be claimed that:

It can be claimed that Dagbasi adopts free translation approach and aims to create a simple language in Turkish by applying to the reductions from time to time to reach a simple and concise translation. On the other hand, although Demirayak preferred to stay close to the target culture in some cases, especially in the 
translation of idioms, he mostly did his translation by sticking to the source text. Therefore, in some cases, it was inevitable to use expressions that are not accepted in the target culture in his translation. If it is true, he did not subtract almost any expression in the source text, and at the same time, he made translations in accordance with the target culture norms and made his translation without ignoring the target culture. Finally, it can be claimed that all the translators aim to create a sufficient and acceptable translation. However, when we consider the approaches they preferred mostly, it is recognized that Dağbaşı and Doğru are trying to create an acceptable translation text; while Demirayak has produced an adequate translation text with a loyal approach focused mostly on source language and culture.

Keywords: Arabic, Translation criticism, Saâdetu'l-Beyk, Competence, Acceptability

Öz: Çeviri yalnızca diller arası değil, aynı zamanda kültürlerarası bir etkinliktir. Çevirmen çeviri sürecinde kaynak metne sadakati ve hedef dil okurunun beklentilerini yerine göre sürekli göz önünde bulundurmalıdır. Yazın çevirmeninin amacı, dilsel işlevi yönünden kaynak metne eşdeğer bir metin ortaya koymaktır. Ancak buradaki eşdeğerlilik yalnızca dilsel gösterge ya da içerik düzeyinde özdeşlikle değil, bir ifadenin iletişimsel işlevinin farklı bir dil ve kültürde korunmasıyla sağlanır. Çeviri metin, kaynak metnin dil ile kültür normlarını gerekli ölçüde taşımalıdır. Çeviri eleştirisi, kaynak metinle hedef metnin karşılaştırmalı çözümlemesini içerir. Bu çözümlemede kaynak ve hedef metinlerin yanı sıra, bunların ait oldukları dizgelerin de göz önüne alınması gerekir. Karşılaştırmalı çözümlemede amaç, hedef metnin çeviri eylemi sırasında etkilendiği unsurları tespit etmek ve kaynak metinden sapmaların nedenini araştırmaktır. Arap edebiyatından dilimize yapılan çeviriler arasında öykü türü önemli bir yer tutmaktadır. Öykü alanında Arapların Maupassant'ı olarak kabul edilen Mîhâ îl Nu ayme, roman, öykü, tiyatro, makale, eleştiri, şiir, biyografi gibi çeşitli türlerde kaleme aldığı eserleriyle, modern Arap edebiyatının en önemli temsilcilerinden biri olarak kabul edilmektedir. Bu çalışmada Mîhâa îl Nu ayme'nin “Saâdetu’l-Beyk”(سعادة البيك) adlı kısa öyküsünden seçilen kesitlerin Erdinç Doğru, Gürkan Dağbaşı ve Kenan Demirayak tarafından dilimize aktarılan çevirileri, karşılaştırmalı çeviri yöntemi ile incelenmiştir. Bu inceleme sonucunda yeterlilik ve kabul edilebilirlik bağlamından hareketle çevirilerin kaynak veya hedef metin odaklılığı, çevirmen kararları arasındaki farklılıklar, çevirmenlerin benimsedikleri çeviri yaklaşımları ve çevirilerin dilbilimsel, sözdizimsel, anlamsal açılardan kaynak metne eşdeğerliğinin ölçüsüne dair birtakım sonuçlara varılmıştır.

Anahtar Kelimeler: Arapça, Çeviri eleştirisi, Saâdetu'l-Beyk, Yeterlilik, Kabul edilebilirlik

\section{Giriş}

Çeviri, kültürler arası iletişimi sağlayan, farklı dilleri konuşan insanların birbirlerinden haberdar olmasına imkân veren dilsel bir etkinliktir. Stolze'ye göre her çeviri bir bakıma başka bir zamana, mekâna ya da kültüre yapılan yolculuktur (Şanverdi, 2019: 241). Bilim ve teknolojinin gelişmesiyle her gün gittikçe küçülen dünyamızda çeviri olgusu hem dil içi hem de diller arası düzeyde iletişimin ayrılmaz bir parçası olarak önemini ve güncelliğini bütün sorunlarıla birlikte korumaktadır (Aktaş, 1996). Çeviri olgusunu salt iki dil arasında uygulanan bir işlem gibi formüle etmek kavramsal anlamda sığ kalacaktır. Kültürel, siyasal, toplumsal, tarihsel değerler çeviri ürününü ortaya koyarken göz ardı edilmemelidir. Her toplum belli normlara göre şekillenir ve bu normlar o toplumun değer yargılarını içerir. Çevirmen her iki toplumun değer yargılarını da zedelemeyecek kararlar almalı, bu bağlamda tarafsızlığını ortaya koyarak ve toplumsal değer sistemini göz önünde bulundurarak gerçeğe uygun bir çeviri yapmalıdır (Uluşahin, 2018: 146).

Edebî çeviride çevirmenin kaygısı kaynak metindeki dilsel ve anlamsal göstergelerin sözlük karşılıklarını bulmak değil; seslendiği kültür ve değerler dizgesi içinde uygun eşdeğerlikleri bulmak olmalıdır. Bu amacı doğrultusunda çevirmen, gerektiğinde kaynak metinden sapabilir. Edebî metin çevirisi, kaynak metin sınırları çerçevesinde, çevirmeni yaratıcı olmaya iter. Çevirmenin çevirisi ile ilgili karalarını ve tercihlerini, kullandığı dil, kültür dizgesi ve yazınsal kurallar 1şığında metni yorumlaması belirler (Aksoy, 2002: 60-61). 
Newmark (1988: 119) kültürel öğeleri sınıflandırması ve bu öğelerin çevirilerinde kullanılan birtakım stratejiler önermesi açısından önemli bir kuramcıdır. Çevirmenin metnin ait olduğu toplumun kültürel değerlerinin farkında oluşu, hedef kültürde aynı etkiyi yaratmak üzere uygun stratejiye karar vermesinde ona yardımcı olur. Çevirmen seçeceği yöntemle, Nida ve Taber'in deyimiyle, kaynak metnin kaynak okurda yarattığı etkiyi çevirisiyle hedef okurda yaratabilmelidir. Bu süreçte, özellikle de kültür bazında karşılaşılabilecek temel zorlukları belirlemek için birtakım eserler incelenerek çeşitli çeviri stratejileri saptanıp daha objektif bir çeviri eleştirisi mümkün k1lınabilir. Burada Venuti'nin yerelleştirme ve yabancılaştırma kavramlarını ele almak gerekir. Bu iki çeviri stratejisi, kaynak metnin nasıl aktarıldığı ve çevirinin hedef kültüre ne kadar yakın olduğuyla ilgilidir. Yerelleştirmede kaynak metin erek dil ve kültüre uygun hale getirilir ve bu arada bazı kayıplar meydana gelebilir. Onun tam tersi olan yabancılaştırmada ise, hedef dile tam uyum sağlanmasa dahi kaynak metnin içeriği olduğu gibi korunur (Tekalp, 2017: 183).

Çeviribilimin inceleme ve uygulama alanlarından biri olan çeviri eleştirisi, basit tanımıyla kaynak metnin dokusunun erek metinde nasıl şekillendiğini karşılaştırmalı olarak inceler. Diğer bir deyişle kaynak metne özgü unsurların anlamsal ve dilsel karşılıklarının çevirmenin seçimlerini eleştirel bağlamda ele alarak, hedef metne nasıl aktarıldığını çözümler (Uluşahin, 2018: 145).

Çeviri eleştirisinde neyin nasıl eleştirileceği konusunun benimsenen kuramsal yaklaşıma göre değişebilmesi, kaçınılmaz olarak çeviri eleştirisi söylemlerinde bir kavram kargaşası ortaya çıkarır. Bu kargaşanın temelini eşdeğerlilik, uygunluk, işlevsellik, kaynak ve erek odaklılık gibi birçok kavramın göreceli olması oluşturmaktadır. Ancak çeviri eleştirisi alanında kuramsal düzlemde ve uygulama alanında yapılan farklı çalışmaların ve erek odaklı kuramlara yönelimin artmasıyla, günümüzde çeviri eleştirisi yalnızca öznel zevklerin, sezilerin ve beğenilerin bir aktarımı olmaktan sıyrılmış, nesnellik ve bilimselliğe doğru bir yönelim yaşamıştır. (Aksoy, 2001: 40; Yücel, 2007: 41).

Reiss ve Nord gibi kuramcılar, çeviri eleştirisi için somut ölçütler belirlemeye çalışmışlardır. Reiss'in yaklaşımını temel alan bir eleştirmenin çevrilen metnin türüne, işlevine ve dilsel niteliklerine bakarak ona göre bir eleştiri yaklaşımı izlemesi beklenir. Örneğin, eleştirilecek olan metin içerik odaklıysa içeriğin iki metinde de örtüşmesi; biçim odaklıysa biçem ve estetik etkinin benzer olması; çağrı odaklıysa metnin alıcıda aynı etki ve tepkiye yol açması belirleyici olmalıdır (akt. Yücel, 2007: 45-46). Ancak bir metnin birden çok işlevinin olabileceğini, çevirmenin ilgili metni bu işlevlerin ağırlık derecesine göre aktarabileceğini de unutmamak gerekir. Eleştirmen işte bu noktaları da eleştirisinde dikkate almak ve buna göre çeviri metnini değerlendirmek zorundadır (Aktaş, 1996:58). Diller arasındaki eşdeğerlilik ilişkisinin tanımlanabilmesi için Reiss, metinlerin 'dil içi' ve 'dil dışı' etmenlerinin saptanması gerektiğini de vurgular. Bir yapıtı çevirmek ve bir çeviriyi eleştirmek için öncelikle bu etmenlerin kaynak metinde çözümlendikten sonra erek metinde ne kadar gözetildiği ya da gözetilmesi gerektiğinin belirlenmesi gerekir. Ancak bu yolla çevirmenin kaynak metinden ne oranda saptığına bakarak, almış olduğu olası kararları eleştirmek 'nesnel' bir yaklaşımın sonucu olarak görülebilir (akt. Yücel, 2007: 46).

Belirli bir dil ve kültürde ya da yazınsal veya akademik bir çevre içinde çeviri eleştirisine nasıl yaklaşıldığı, aynı zamanda çeviriye nasıl yaklaşıldığının bir aynası olabilir. Örneğin, kimi ortamda çeviri eleştirisi edebiyatçılar ve dilbilimciler tarafından yapılırken, kimi ortamlarda çevirmenler birbirlerini öznel yargılarla değerlendirirler. Bazı çeviri eleştirilerinde çeviri sürecine ya da ürününe hiç değinilmeden kaynak metin hakkında genel bir düşünce ortaya konulurken, bazılarındaysa herhangi bir bulguya dayandırmaksızın "çeviri yazarın biçemini yansıtmıştır ya da birkaç küçük hata dışında çok iyi bir çeviri" gibi yargılara varılmaktadır. Bunların yanı sıra hata avcılığına dönüşen çeviri eleştirileri de bulunmaktadır. Bu tür çalışmalardaysa genelde nesnel ve dizgesel ölçütler kullanılmamakta, çevirinin özgün metnin sadık bir aktarımı olması gerektiği anlatılmakta, hedef dil ve kültür ile yazınsal gelenek göz ardı edilmektedir. Tüm bu farklı yaklaşımlar 
çevirinin, çeviri okuyucusunun, çevirmenin, çeviri akademisyeninin belirli bir dil ve kültür içindeki profesyonellik derecesinin yansitımı olabilmektedir (Karantay, 1987: 51-55; Paker, 1983: 131-139).

Berman, çeviri eleştirisinde amacın çevirmenin hatalarını sergilemek değil, kaynak metinle çeviri metin arasındaki farklılıklar dizgesini ve bu dizgenin nasıl işlediğinin incelenmesi olduğunu belirtir (akt. Rifat, 2008: 145). Başarısız bir çevirideki yetersizlikler, büyük bir kolaylıkla, yanlış doğru mantığıyla göz önüne serilebilmektedir. Gerçekte sözlük anlamlarından yola çıkarak, bir çeviriyi kötülemek ve hata avc1lığı yapmaktan daha kolay bir şey yoktur. Ne var ki, sözcük düzeyinde bu yanlış-doğru kovalamacasının, çeviri eleştirisinde bir yeri yoktur (Göktürk, 1994: 91). Yanlışdoğru ayrımından ziyade çeviri etkinliğini bir süreç olarak ele alıp bu süreçte meydana gelen değişiklikleri, ayrımları, çevirinin kendi dinamiklerine göre betimleyip tanımlamak çok daha gerçekçi ve yararlı sonuçlara ulaşılmasına katkı sağlayacaktır (Paker, 1988: 116-121). Kaynak dil ile hedef dil, özgün metin ile çeviri metin arasında yapılacak ayrımsal karşılaştırmalarla, tek tek yanlışlar ötesinde, benzer türden yanlışların nedenleri, işlenme olasılıkları dizgeli bir biçimde ortaya konursa, yapıcı bir eleştiriye doğru adım atılmış olacaktır (Göktürk, 1994: 91).

Çeviribilimde ortaya konulduğu şekliyle çeviri eleştirisi yapabilmek için bu uğraşın sınırlarını ve gerektirdiklerini çok dikkatli belirlemek gerekmektedir. Her şeyden önce eleştirmen çeviri uğraşını yakından bilmelidir. Çeviri uğraşının neler gerektirdiğini, çevirmenin görevinin ne olduğunu, çeviri sorunlarının hangi yöntemlerle aşılabileceğini bilmeli, hedef dil ve kültürdeki çeviri geleneğini tanımalıdır. Ayrıca eleştirmen kaynak metni dizgesel bir şekilde dil, kültür, ileti ve yazınsal özelliklerinin üzerinde durarak inceleyebilmelidir. Bunun devamında, aynı süreci karşılaştırmalı olarak çeviri metin üzerinde gerçekleştirebilmelidir. Bu süreçlerin sonucu olarak ortaya çıkan verileri karşılaştırabilmeli ve bunları nesnel ve öznel olarak çeviri kuramı ve çevirikaynak yazınsal gelenekleri çerçevesinde değerlendirebilmelidir (Aksoy, 2001: 2).

Çeviribilim çerçevesinde dizgesel ve kullanılabilir, kapsamlı, betimleyici ve hedef odaklı çeviri eleştirisi için çeviri eğitiminde kullanılabilecek en iyi yöntemin Van den Broeck'ın betimleyici çeviri eleştirisi yöntemi olduğu söylenebilir. Bu yöntem, çeviribilimi tüm geçmiş ve gelecek uygulamalarıyla bütünleştiren nesnel ve geniş kapsamlı bir yöntemdir (Aksoy, 2002: 166-167). Van den Broeck'un önerdiği betimleme modeline göre, bir çevirinin yeterli, doğru, başarılı olup olmadığının araştırılması, o çevirinin "neden"lerinin ve "nasıl"larının yanında ikinci planda kalır. Çevirmen neden belli normları benimser? Neden belli seçimler yapar? Onun çalışmasını güçleştiren hangi nedendir? Bu koşullar çeviri sürecini ve çeviri ürününü nasıl etkiler? Bu soruların yanıtları çok önemlidir (akt. Rifat, 2008: 136). Çeviri eleştirisinin bir yöntem doğrultusunda incelenmesini savunan Van den Broeck, önce özgün metinle çeviri metnin karşılaştırmalı çözümlemesinin yapılması gerektiğini savunur. Bu çözümleme sessel, sözcüksel, söz dizimsel düzeyleri ve dil değişkelerini söz sanatlarını, anlatısal ve şiirsel yapıları ve metinsel imleri (noktalama işaretleri, paragraf düzenlemesi gibi), kurgusal özellikleri ve benzeri öğeleri kapsar. İkinci aşamada kaynak metinde bulunan özellikler çeviri metinde aranır ve bu bağlamda karşılaştırmalı dilbilim ve biçembilim yöntemleri ve bilgileri kullanılır. Üçüncü aşamada yeterli çeviriyi oluşturacak koşullar iki dilin ve kültürün olanakları çerçevesinde değerlendirilir ve olası sapmalar ve kaymalar saptanır. $\mathrm{Bu}$ üç aşamadan sonra eleştirmen artık çevirinin nasıl, neden, ne amaçla ve ne sonuçla yapıldığını neden bu seçimlerin ortaya konulduğunu yanıtlamaya çalışacaktır. $\mathrm{Bu}$ aşamada eleştirmen seçimlerini, yargılarını ve bunların somut nedenlerini çeviri metni oluşturan tüm unsurlar kapsamında sunabilmelidir. Eleștirmen böylece hem nesnel hem de öznel olan bir değerlendirmeyi tamamlamış olacaktır (Aksoy, 2001: 4-5).

Van den Broeck, dizgeli yönteminde Anton Popovic'in ortaya koyduğu "deyiş kaydırma" kavramından çok yararlanır. Popovic, kaynak metinden ayrılıkları, gerçek bir yanlış söz konusu değilse birer yanlış olarak değil, "kaydırma" olarak niteler ve bu ayrılıkları, kaynak metni en iyi şekilde hedef dilde yaratabilmek için yapılan değişiklikler olarak görür. Buna bağlı olarak, çeviri 
eleştirisinde kesin bir doğru ya da yanlıştan söz etmekten çok seçimlerden söz etmek daha doğru olacaktır (akt. Aksoy, 2002: 167-168). Sonuç olarak Van den Broeck'un modelinde gördüğümüz, salt kaynak metin-hedef metin karşılaştırmasına dayanmayan bu yaklaşımın, daha sağlıklı ve daha bilimsel çeviri eleştirileri yazmaya olanak sağladığını söyleyebiliriz (akt. Rifat, 2008: 136).

Toury ise çevirinin, toplumbilimsel bir kavram olan normlar tarafından belirlendiğini ifade eder ve çevirinin her aşamasında çok etkin bir rol oynayan üç tür norm belirler. Bunlar süreç-öncesi normlar, süreç normları ve öncül normlardır (akt. Ünsal, 2017: 245). Süreç öncesi normlar, çevirinin doğrudan kaynak dilden yapılıp yapılmadığını ve kaynak kültüre ilişkin ölçütleri içeren bir çeviri anlayışının bulunup bulunmadığını belirler (Tahir Gürçağlar; 2011: 136-137; Bengi, 1993: 32-33). Çeviri süreci normları, çevirmenin çevirisini yaparken aldığı kararları yöneten normlardır. Çeviride dilin nasıl kullanılacağ nasıl olacağı gibi kararlar bu normla ilgilidir (Dağbaşı, 2017: 1412). Öncül norm ise çevirmenlerin yaptıkları çevirilerde kaynak metin ve kültürün normlarına $\mathrm{m}$, yoksa hedef dil ve kültürün normlarına $\mathrm{m} ı$ daha yakın duracaklarını belirler. Eğer çevirmen kaynak metne daha yakın duruyorsa çeviride 'yeterlik', hedef metne daha yakın duruyorsa 'kabul edilebilirlik' söz konusudur. Burada 'yeterlik' kavramının 'sadık', 'kabul edilebilirlik' kavramının 'serbest' çeviri ile özleștirilebileceği söylenebilir (Tahir Gürçağlar; 2011: 136-137; Bengi, 1993: 32-33).

Çeviri eleştirisinde eleştirmen, çevirmenin çeviri sürecinde bu iki kavramdan hangisine ağırlık verdiğini belirleyerek çevirinin "yeterli" mi yoksa "kabul edilebilir" mi olduğunu ortaya koyabilmelidir (Yalçın, 2003: 37). Bu süreç içinde aşağıdaki noktalar önem kazanır:

a) Eleştirmen, değerlendirme sürecinde çevirmenin dil kullanım tercihlerini bir bütünlük içinde ele almalı,

b) Eleştirmen, çevirmenin hedeflediği okuyucu kitlesinin beklentisi ve beğenisine göre belirlediği çeviri yöntemini ortaya koyabilmeli,

c) Eleştirmen, bu amacı gerçekleştirmeye yönelik seçimlerini ve tutumlarını belirleyebilmelidir (Dağbaşı, 2017: 1413).

\section{Modern Arap Kısa Öykücülüğüne Genel Bir Bakış}

Kısa öykü türü ilk defa 19. asırda ortaya çıkmıştır. Bu türü ilk kez ortaya çıkaran, Amerikalı yazar Edgar Allan Poe'dur. Poe'dan sonra aynı türde eserler veren usta edebiyatçılar sayesinde de kısa öykü türü tüm dünya ülkelerine yayılmıştır (Tasa, 2006: 133).

Arap edebiyatında kısa öykü ise, bazı edebiyat araştırmacıları ve eleştirmenleri tarafından Binbir Gece Masallarına, Antara Efsanelerine, Hayy bin Yakzân'a ve Makâmeler'e kadar dayandırılırken; Tâhir Ahmed Mekkî gibi bazı edebiyat eleştirmenleri kısa hikâyenin Arap edebiyatında var olmadığı ve Batı etkisinde ortaya çıktığı görüşündedir. Modern Arap Edebiyatında kısa öykünün dayandığ 1 temel noktasındaki görüş ayrılıklarına rağmen edebiyat eleştirmenleri ve araştırmacıları arasındaki ortak görüş, bu türün Arap dünyasına modern anlamda 19. yüzyılda yaşanan Edebî Rönesans (en-nahda) ile girerek söz konusu dönemin son yıllarında geliştiği ve ancak 20. yüzyılın ilk yıllarında olgunlaştığı olmuştur (Suçin, 1998: 14; Mekkî, 1999: 109). Bu dönemde sosyal problemler yaşayan Arap dünyasında, kısa hikâye sayesinde bir canlanma görülmüştür. $\mathrm{Bu}$ canlanmayı sağlayanların başında, Amerika Birleşik Devletleri'ne giden Lübnanlı Cibrân Halîl Cibrân gelmektedir (Emekli, 2006: 11-12).

Birinci Dünya Savaşı'nın ardından Arap dünyasındaki ülkelerin İngiliz kolonisi haline gelmesi, Arap toplumunda yabancılara karşı olan mücadelede ulusal bilincin gelişmesini sağlamıştır (Demirci, 2014: 15). Ulusal bilincin oluşmasıyla bölgedeki sömürgeye karş1 olan ayaklanmalar, modern Arap öyküsünün doğmasına zemin hazırlamıştır. Bu ortaya çıkan yeni türün öncüleri arasında, Mısır'da Muhammed Teymûr, Lübnan'da Lebîbe Hâşim, Abdulmesîh Haddâd ve Mîhâil 
Nu'ayme, Filistin'de Halîl Baydas, Irak'ta Mahmûd Ahmed es-Seyyid'i sayabiliriz. Arap kısa hikâyeciliğin önderi olarak ise Selîm Butrûs el-Bustânî kabul edilmektedir (Hafiz, 2003:7). Ayrıca Arap edebiyatında modern anlamda ilk kısa öykünün Misırlı yazar Muhammed Teymûr tarafindan kaleme alınan ve 1917'de "es-Sefûr" gazetesinde yayımlanan "Fî'l-Kitâr" olduğu kabul edilir (Yıldız 2002: 46). Ayrıca Mîhâîl Nu'ayme'nin "el-Akîr" ve "Senetuhe'l- Cedîde" adlı öyküleri ile Mustafa Lutfî Cum'a'nın "fi Buyûti'n-Nâs" adlı öykü koleksiyonu da bu türün ilk örneklerini teşkil eder (Çetişli, 2009: 67).

\section{Mîhâîl Nu'ayme}

Mîhâîl Nu'ayme 1889 yılında Ortodoks bir ailenin üçüncü çocuğu olarak Lübnan'da dünyaya gelmiştir. 1902 yılında, Filistin Nasıra'daki Rus Öğretmen Okuluna kayıt yaptımış, ardından bu okuldaki 4. yılında üstün başarısından dolayı burslu olarak 1906 yılında Rusya'nın Poltava şehrindeki Ortadoks Akademisine gönderilmiş̧tir (Türkan, 2011: 38-39). Rusya' da kaldığı zaman zarfında Rusçayı iyi derecede öğrenmiş ve burada Rus edebiyatının devleriyle tanışarak onların üsluplarından yararlanma firsatı bulmuştur. Nu'ayme, ilk kasidesi olan "en-Nehru'lMutecemmide"yi burada öğrenciyken Rusça olarak kaleme almıştır (Hamidov, 2015: 197).

Nasıra'daki eğitimi esnasında tanıștığı Nesib 'Arida'nın kurmuş olduğu el-Funûn adlı dergide yenilikçi yazılarıyla dikkatleri üzerine çekmiştir. Bu dergide kendisi gibi el-Funûn' da yazılar yazan Cibrân Halîl Cibrân, Abdulmesih Haddad, Reşid Eyyub ve İlya Ebû Madi gibi yazarların bulunduğu 10 kişilik bir heyetle er-Rabitatu'l-Kalemiyye derneğini kurmuşsa da 1920 yllında faaliyete başlayan dernek çok uzun ömürlü olmamış; 1931 yılında Cibran'ın vefatıyla birlikte kapanmıștır (Türkan, 2011: 40-41). Arkadaşının ölümünden bir yıl sonra Lübnan'a kalıcı dönüș yapan Nu'ayme, 21 yıllık göç serüveni esnasında sadece iki kitap yayınlamıştır. Bu kitaplar, "el- 'Âbâ ve'l-benûn" adlı tiyatro eseriyle, el-Funûn dergisinde ve es-Sâih gazetesinde yayınlanan eleştiri ve edebiyata dair makalelerinin toplandığı "el-Ğirbâl" adı eseridir (Hamidov, 2015: 187; Türkan, 2011: 42).

Nu'ayme, geleneksel dil anlayışına bağlı olanları sert bir dille eleştirerek eskiyi taklide karşı çıkmıştır. Üslubuna gerçekçilik, sadelik, akıcılık hâkimdir ve Arap edebiyatının genel özelliği olan uzatmalar ve doldurma ifadelerden uzak durmuştur. Fasih ve halk dili kullanımlarına da değinen Nu'ayme, halk dilinin kullanılmasının kaçınılmaz olduğu yerlerin var olduğunu savunur. Örneğin, okuma yazma bilmeyen bir çiftçiyi, şiir divanlarının ve dil kitaplarının lisanıyla konuşturmanın, yazarı komik bir duruma düşüreceği görüşündedir. Ona göre söylenmek istenen şeyi hangi dil daha iyi ifade edecekse onu kullanma zorunluluğu vardır (Hamidov, 2015: 193-195).

\section{Eser}

"Saâdetu'l-Beyk", Modern Arap Edebiyatının önemli bir aşamasını teşkil eden "Göç Edebiyatı"nın öncü isimlerinden Mîhâil Nu'ayme'nin "Kâne mâ Kâne" adlı öykü koleksiyonunun en güzel öykülerinden biri olarak kabul edilir (Koç 2013: 50-53).

Söz konusu eser, Türkçeye Kenan Demirayak (2000) tarafından Kısır adlı çeviri seçkisi içinde "Bey Hazretleri” başlığıyla; Erdinç Doğru (2002) tarafından Onuncu Günde Kaplanlar adlı çeviri seçkisi içinde "Beyefendi" başlı̆̆ıyla çevrilmiştir. Gürkan Dağbaşı’nın (2017) çevirisi ise Türkçe Çevirileriyle Arapça Kısa Öyküler adlı çeviri seçkisi içinde "Bey Hazretleri" başlığıyla yayımlanmıştır. Eser kısaca şu şekilde özetlenebilir:

Olay örgüsü Amerika'nın Newyork eyaletinde, anlatıcının arkadaşıyla gitmiş olduğu Ebû 'Assâf' in lokantasında geçmektedir. Öykü, Ebû 'Assâf'ın, onlara her gün aynı saatte lokantasına gelen "Bey Hazretlerinin" hikâyesini anlatması üzerine başlamış olur. Ebû 'Assâf, onun gerçek adının Esad ed-Da'vak olduğunu, Lübnan' da uzun yıllar şeyhlik görevini yürüten ed-Da'vak ailesine mensup olduğunu, ancak ailenin emri altında çalışanların Amerika'ya gidip oradan zengin olarak dönmeleri neticesinde ed-Da'vak ailesinin arsalarını satın aldıklarını, nihayetinde sonuncu varis olan 
Şeyh Es'ad'ın, dedelerinin kendisine bıraktı̆̆ borcun altında bölgenin yönetimini elinde tutmaya çalıştığından bahseder. Ancak emri altındaki hizmetçilerden biri olan Ravkes Nasûr' un Amerika' da zengin olarak memleketine dönüp valilikten "Bey" ünvanını satın almasıyla Şeyh Esad'ın halk arasındaki itibarı ve prestiji sona erer. Şeyh Es'ad, bu durum karşısında bunalıma girer ve ortadan kaybolur.

Ancak sonra bir anda çıkagelir ve valilikten "Bey" unvanını satın aldığını, bundan sonra kendisine "Es'ad Bey Hazretleri” diye hitap etmeleri gerektiğini söyler. Bu sayede halk arasındaki itibarını yeniden kazanır. Ancak Ravkes' in valiliğe gidip işin iç yüzünü öğrenmesiyle Es'ad'ın yalan söylediği, valiliğin Es'ad'a "Bey" unvanını vermediği ortaya çıar. Böylece Şeyh Es'ad'ın yalanı ortaya çıkar ve bir müddet sonra da temelli ortadan kaybolur.

Bunları anlatan lokantacı Ebû 'Assâf, bir müddet sonra kendisinin de Amerika ya göç ederek orada bir lokanta açtığını ve müşterilerin konuşmalarından Şeyh Es'ad'ın da Amerika' da olduğunu öğrendiğini anlatır. Birkaç gün geçmeden Şeyh lokantaya gelir. Ebû 'Assâf' in selamını bile almadan, kendisine "Bey Hazretleri" diye hitap etmediği için onu azarlar. Ebû 'Assâf, onun lokantasına geldiği ilk günden bugüne kadar yedi yıl geçtiğini, her zamanki gibi saat 21.30 gibi lokantaya girdiğini, bir şeyler yiyip içtikten sonra "-Hesabıma yaz" diyerek para vermeden çekip gittiğini anlatır. Kendisinin de onun haline üzülüp Allah rızası için ikramda bulunup para istemediğini söyler ve öykü burada son bulur (Türkan, 2011: 63-64).

\section{Kaynak ve Hedef Metin Kesitlerinin Karşılaştırılması}

\begin{tabular}{|c|c|}
\hline Nu'ayme (2000: 94) & فبادرناه بالسؤال سوية بفم واحد: من هو "البيك" يا أبا عسّاف؟ \\
\hline Dağbaşı (2017: 151) & $\begin{array}{l}\text { Sanki arkadaşımla önceden sözleşmiş gibi ona tek bir ağızdan sorduk: } \\
\text { - "Bey" kim ey Ebâ Assâf? }\end{array}$ \\
\hline Doğru (2002: 102) & Hemen ona, "Beyefendi de kimdir, Ebû Assâf" diye sorduk hep bir ağızdan. \\
\hline Demirayak (2000:79) & $\begin{array}{l}\text { Aynı anda arkadaşımla bir ağızdan soruyu yöneltiverdik: } \\
\text { - "Bey" de kim Ebû Assâf? }\end{array}$ \\
\hline
\end{tabular}

Doğru, iki cümleden oluşan bu kesiti hedef metne tek bir cümle olarak aktarırken, Dağbaşı ve Demirayak'ın bu konuda kaynak metne sadık kalarak çevirilerini yaptıkları görülmektedir. Dağbaşı bir eylemi hızlıca yapmak anlamındaki بادر fiilinin aktarımında geniş bir açımlama yaparak anlamı güçlendirmeye çalışmıştır. Demirayak ve Doğru ise kaynak metne sadık bir çeviriyi tercih ederek herhangi bir ekleme veya çıkarma yapmamışlardır. Kaynak metindeki بفم واحد deyiminin aktarımı için üç çevirmenin de farklı tercihler yaptığını görmekteyiz. Her üç çeviri de hedef dilde kullanılan ifadelerdir. Çevirmenler öykünün ana kahramanı olan Esad Davak'ın ünvanını, başlık tercihlerinde de olduğu gibi 'Bey' ve 'Beyefendi' olarak iki farklı ifadeyle karşılamışlardır. Son olarak kaynak metindeki Ebû Assâf ismi, Arapçanın dil bilgisel kuralları sebebiyle kaynak metinde Ebâ Assâf olarak geçmektedir. Dağbaşı bunu kaynak metinden sapmayarak transkripsiyon yoluyla hedef dile aktarırken, Doğru ve Demirayak ismin aslını kullanmayı tercih etmişlerdir. 


\begin{tabular}{|c|c|}
\hline Nu'ayme (2000: 95) & 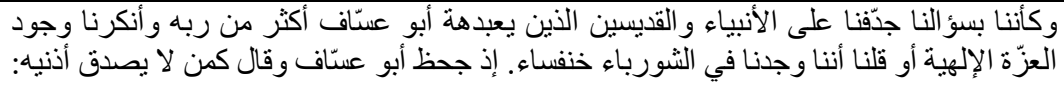 \\
\hline Dağbaşı (2017: 151) & $\begin{array}{l}\text { Sanki peygamberlere, evliyalara küfretmişiz, Allah'ın izzetini, uluhiyetini } \\
\text { inkâr etmişiz ya da yemekte bok böceği bulduğumuzu söylemişiz gibi } \\
\text { sorumuz Ebû Assâf'1 şaşırtmıştı, gözleri dışarı fırladı, kulaklarına } \\
\text { inanamayan biri edasıyla sordu: }\end{array}$ \\
\hline Doğru (2002:102) & $\begin{array}{l}\text { Bu sorumuzla sanki Ebû Assâf' } 1 \text { n, rabbinden daha fazla taptığ1 } \\
\text { peygamberlere ve kutsal azizlere küfretmiş ve ilahi kudretin varlığını inkar } \\
\text { etmiş yahut çorbanın içinde bir bok böceği bulduğumuzu söylemişiz gibi } \\
\text { gözlerini fal taşı misali açarak, kulaklarına inanamayan bir kimse gibi: }\end{array}$ \\
\hline Demirayak (2000: 80) & $\begin{array}{l}\text { Ebû Assâf'ın gözlerinin fal taşı gibi açılmasına bakılırsa bu sorumuzla Ebû } \\
\text { Assâf'ın rabbinden daha çok inandığı peygamberlere ve azizlere } \\
\text { küfretmiştik ve kutsal saygınlığı inkâr etmiştik sanki yahut çorbada böcek } \\
\text { çıktığını söylemiştik. Kulaklarına inanamayan bir kimsenin edasıla şöyle } \\
\text { dedi: }\end{array}$ \\
\hline
\end{tabular}

Öyküde geçen karakterlerden biri olan Ebû Assâf'ın duyduğu şaşkınlığı anlatan bu cümlede Doğru, herhangi bir ekleme veya eksiltmenin bulunmadığı sözcüğü sözcüğüne çeviri yapmıştır. 'Gözü pörtlemek' anlamındaki جحظ fiilini Türkçedeki eşdeğeri olan 'çok şaşırmak' anlamındaki deyimle karşılamıştır. Dağbaşı ve Demirayak ise hedef dile yakın durarak ve kaynak metindeki bazı sözcükleri eksilterek çeviri yapmayı tercih etmişlerdir. Ayrıca Demirayak'ın kaynak metindeki söz öbeklerinin sıralamasını değiştirerek aktardığı gözükmektedir. O da جحظ fiilini Doğru'yla aynı şekilde hedef dil odaklı çevirmiştir.

\begin{tabular}{|c|c|}
\hline Nu'ayme (2000: 95) & 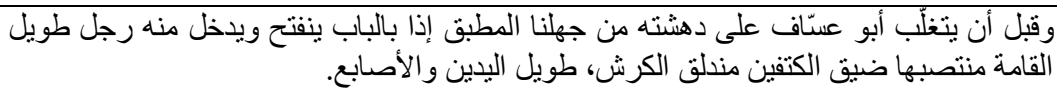 \\
\hline Dağbaşı (2017: 152) & $\begin{array}{l}\text { Ebû Assâf cehaletimizden kaynaklanan şaşkınlığından kurtulamamıştı ki } \\
\text { kapı açıldı ve içeri uzun boylu, dik yapıll, dar omuzlu, koca göbekli, uzun } \\
\text { elli ve parmaklı biri girdi. }\end{array}$ \\
\hline Doğru (2002: 102) & $\begin{array}{l}\text { Ebû Assâf, henüz bizim kara cehaletimizden kaynaklanan şaşkınlığını } \\
\text { yenemeden ansızın kapı açıldı ve oradan uzun boylu, dik yapıll, omuzları } \\
\text { dar, göbeği sarkık, elleri ve parmakları uzunca bir adam içeri girdi. }\end{array}$ \\
\hline Demirayak (2000: 80) & $\begin{array}{l}\text { Ebû Assâf kör cehaletimiz karşısındaki şaşkınlığını henüz yenememişti ki } \\
\text { bir de ne görelim, kapı açıldı ve içeriye uzun boylu, dar omuzlu, göbeği } \\
\text { çıkık, elleri ve parmakları uzun biri girdi. }\end{array}$ \\
\hline
\end{tabular}

Buradaki çevirilerin birbiriyle benzer olduğunu söyleyebiliriz. Ancak bazı noktalarda çevirmenler farklı çeviri yapmayı tercih etmişlerdir. مطبق kelimesi, hemen öncesinde gelen 'cehalet' anlamındaki kelimenin şiddetini belirtmek amacıyla kullanılmıştır. Ancak Dağbaşı kelimeyi eksilterek bu anlamı hedef dile hafifleterek aktarmıştır. Demirayak ve Doğru ise hedef dildeki eşdeğeri bularak iki farklı tercihte bulunmuş ve kaynak metindeki vurguyu hedef dile taşımışlardır. Ayrıca bir şeyin ansızın, sürpriz bir şekilde olduğunu ifade eden lإٍ harfi de her üç çevirmen tarafından farklı aktarılmış. Dağbaşı kaynak dilde harf olarak kabul edilen bu ögeyi hedef dilde kelime kabul edilen bir ifadeyle karşılamak yerine, şaşkınlık ifade eden '-ki' bağlacıyla karşılayarak hem biçimsel hem de anlamsal olarak kaynak metne sadık kalmıştır. Demirayak daha serbest bir çeviriyi benimsemiştir ve hedef metinde oluşturduğu cümleye öykü kahramanlarının duyduğu şaşkınlığı okuyucuya daha fazla hissettiren 'bir de ne görelim' eklemesini yapmıştır. Doğru ise 'ansızın' zarfinı kullanmayı tercih etmiştir. Dikkat çeken bir diğer çeviri farkı da Bey'in fiziğini niteleyen مندلق الكرش tamlamasında görülüyor. Sözlük anlamında 'akan sıvı bir madde' olarak çevrilebilecek مندلق kelimesi burada göbek kelimesini nitelemektedir. Bu anlamda üç çevirmenin de tercihi hedef dilde kullanışlılık açısından yerinde olmuştur. Sonuç olarak Dağbaşı ve Demirayak'ın 
çevirilerinde bir takım ekleme ve çıkarmalar bulunurken; Doğru'nun çevirisi kelime düzeyinde eşdeğerlik bakımından ekleme ve çıkarmaların olmadığı, kaynak metne sadık bir çeviri olmuştur.

\begin{tabular}{|c|c|}
\hline Nu'ayme (2000: 95) & 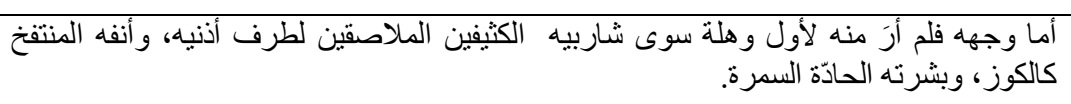 \\
\hline Dağbaşı (2017: 152) & $\begin{array}{l}\text { Yüzüne gelince ise ilk bakışta sık bıyıkları, kafasına yapışık kulakları, } \\
\text { balkabağı gibi şişkin burnu ve koyu esmer teninden başka bir şey } \\
\text { gözükmüyordu. }\end{array}$ \\
\hline Doğru (2002: 102) & $\begin{array}{l}\text { Yüzüne gelince, ilk bakışta dikkatimi çeken şey onun kulak memelerine } \\
\text { kadar uzanan pala bıyıkları, maşrapa misali şişkin burnu ve koyu kahverengi } \\
\text { teniydi. }\end{array}$ \\
\hline Demirayak (2000:80) & $\begin{array}{l}\text { Yüzü ise; yüzünden ilk anda kulaklarının uçlarına yapışmış kalın } \\
\text { bıyıklarından, testi gibi şiş burnundan ve ince esmer teninden başka bir şey } \\
\text { görmedim. }\end{array}$ \\
\hline
\end{tabular}

Öykünün kahramanı olan Bey’in yüzünün betimlendiği bu cümlenin yükleminin çevirisi için üç çevirmenin de farklı tercihler yaptığı görülmektedir. Doğru, öznesi birinci tekil şahış olan bu olumsuz fiil cümlesinin türünü değiştirmiş ve isim cümlesi olarak hedef dile aktarmıştır. Demirayak çevirisinde kaynak metne bağlı kalırken, Dağbaşı 'görmek' anlamındaki fiili 'gözükmek' olarak kaydırmıştır. Dağbaşı’nın, Bey’in bıyık şeklini tarif eden شاربيه الكثيفين الملاصقين لطرف أذنيه ' ifadesini iki farklı tamlama gibi ele alarak الملاصقين kelimesini bıyık yerine kulağın sıfatı olarak aktarması anlam kaymasına neden olmuştur. Yine bu tamlamada tarif edilen bıyığın şekli üç çevirmenin zihninde de değişik canlanmış olacak ki birbirinden farklı türlerdeki bıyıkları tarif eden sıfatlar kullanmışlar. Doğru, hedef dilde kulaklara doğru kıvrık ve gür bıyığı tarif eden pala bıyık ifadesini kullanmıştır. Dağbaşı daha genel bir ifadeyle sık bıyık şeklinde bir aktarım yaparken, Demirayak bunu kalın bıyık tamlamasıyla karşılamıştır. كثيف kelimesinin sözcük anlamına bakıldığında da Doğru'nun hedef odaklı bir aktarımda bulunduğu, Dağbaşı ve Demirayak'ın ise kaynak metne daha sadık kaldığı görülüyor. Beyin burnunun büyüklügünü betimleyen كوز sözcügü Türkçede testi, maşrapa, ibrik gibi anlamlara gelir. Demirayak ve Doğru sözcügü sözcüğüne çeviri yaparak kaynak metne sadık kalmış; Dağbaşı ise kelimeyi 'balkabağı' olarak kaydırarak balkabağının yuvarlak ve büyük oluşundan faydalanmıştır. Bey'in yüzüyle ilgili son bahsedilen şey olan ten renginin aktarımında da farklı tercihler görüyoruz. Demirayak, Bey'in esmerliğinin yoğunluğunu ifade eden حادّ sifatını 'ince' olarak aktararak anlam kaymasına sebebiyet vermiştir. Dağbaşı kaynak metne sadık kalarak 'koyu esmer' şeklinde bir çeviri yapmış, Doğru ise esmer sözcüğünün zaten koyu ten rengi olduğunu düşündüğünden olacak esmer yerine 'koyu kahverengi' ifadesini kullanmış. Ancak hedef dilde cilt renginin betimlenmesinde kahverenginin çok kullanılan bir sıfat olmaması sebebiyle Doğru'nun tercihinin hedef dilin kullanım alanı açısından yaygın olmadı̆̆ı söylenebilir.

\begin{tabular}{|c|c|}
\hline Nu'ayme (2000: 95-96) & 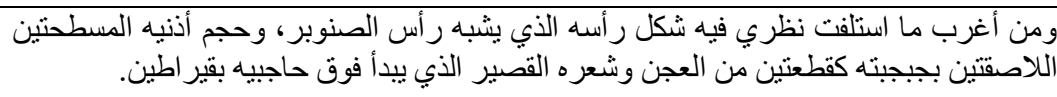 \\
\hline Dağbaşı (2017: 152) & $\begin{array}{l}\text { Bana tuhaf gelen, dikkatimi çeken çam kozalağına benzeyen kafası, iki } \\
\text { parça hamur gibi kafatasına yapışmış kulaklarının büyüklüğ̈u, kaşlarının } \\
\text { hemen üstünden başlayan kısa saçlarıdı. }\end{array}$ \\
\hline Doğru (2002:102) & $\begin{array}{l}\text { Dikkatimi çeken en tuhaf şey ise, başının bir çam kozalağına benzeyen şekli, } \\
\text { iki hamur parçası gibi kafasına yapışı olan yayvan kulaklarının büyüklügü } \\
\text { ve kaşlarının beş cm yukarısından başlayan kısa saçı idi. }\end{array}$ \\
\hline Demirayak (2000: 80) & $\begin{array}{l}\text { Onda dikkatimi en fazla çeken şey kafasının çamın başına benzer şekli, } \\
\text { kafatasına hamur parçası gibi yapışmış yayvan iki kulağının büyüklüğü ve } \\
\text { kaşlarının iki parmak yukarısında başlayan kısa saçı idi. }\end{array}$ \\
\hline
\end{tabular}

Bey’in yüzünün betimlenmeye devam edildiği bu cümlede, çevirmenler cümle ögelerine sadık kalarak genel anlamda birbirlerine yakın çeviriler yapmışlar. Demirayak'ın kaynak metne sıkı 
s1kıya bağlı kalarak رأس الصنوبر sözcügünü 'çamın başı' olarak çevirmesi, hedef dil okuyucusunun zihninde karışıklığa neden olabilir. Zira bu ifadeyle kastedilen şekil, dolayısıyla da Bey'in kafasının şekli tam anlaşılmayarak okuyucuların zihninde tek ve net bir görüntünün canlanmasını engelleyebilir. Dağbaşı ve Doğru bu ifadeyi hedef odaklı bir yaklaşımla 'çam kozalağı' olarak aktararak ifadeyi netleştirmişlerdir. Bu üç çeviri arasındaki en dikkat çekici farklılık çevirmenlerin parmak ölçü birimi olan ve iki parmağa tekabül eden قير اطين sözcügünün aktarımı için tercih ettikleri karşılıklardır. Beyin kaşı ve saçı arasındaki açıklığın ne kadar olduğunu ifade eden bu ölçü biriminin aktarımı için Dağbaşı net bir birim kullanmayarak mesafenin kısa olduğunu belirten daha esnek bir ifade ile aktarım yapmayı tercih etmiştir. Demirayak kaynak metinde kullanılan kelimeden sapmadan ölçüyü biraz daha netleştirmiştir. Doğru ise diğer çevirmenlerden farklı olarak modern bir uzunluk ölçüsü olan 'cm' kavramını kullanmıştır. Ancak bu cümlede Bey'in yüzü anlatıcının yaptı̆̆ı gözlemle betimleniyor. Dolayısıyla burada cetvelle ölçülmüş gibi net bir ölçü kullanılmasındansa, gözlem sonucunda yaklaşık olarak söylenebilecek daha esnek bir ifade kullanılması cümlenin bütünlüğünün korunması açısından daha uygun olabilirdi. Ayrıca bu kullanım, okuyucuda edebi bir metinden bilimsel bir metne geçiş yapıyor hissi uyandırarak metnin akıcılığını olumsuz etkileyebilir.

\begin{tabular}{|c|c|}
\hline Nu'ayme (2000: 96) & 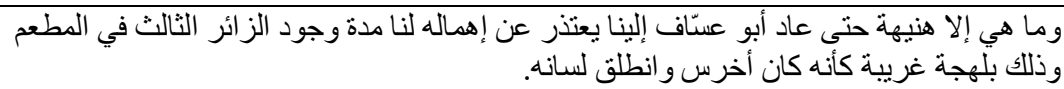 \\
\hline Dağbaşı (2017: 152) & $\begin{array}{l}\text { Bir dakika bile geçmemişti ki Ebû Assâf yanımıza geldi ve bizi ihmal ettiği } \\
\text { için özür diledi. Bunu söylerken sanki dilsizmiş de dili yeni çözülmüş gibi } \\
\text { garip bir şiveyle konuşuyordu. }\end{array}$ \\
\hline Doğru (2002: 103) & $\begin{array}{l}\text { Kısa bir süre sonra Ebû Assâf yanımıza dönerek, bu üçüncü konuğun } \\
\text { lokantada olduğu süre içinde bizi ihmal ettiğinden dolayı özür diledi. Bunu } \\
\text { sanki dilsizmiş de dili çözülmüş gibi bir ses tonuyla söyledi. }\end{array}$ \\
\hline Demirayak (2000:81) & $\begin{array}{l}\text { Birkaç dakika geçmişti ki Ebû Assâf lokantada üçüncü müşterinin varlığı } \\
\text { süresince bizi ihmal ettiği için özür dileyerek yanımıza geldi. Özür } \\
\text { cümlelerini dilsiz biriymiş gibi garip bir telaffuzla sarf ediyordu. }\end{array}$ \\
\hline
\end{tabular}

Çevirilere bakıldığında ilk göze çarpan, çevirmenlerin geçen zamanı aktarmak için kullandıkları farklı ifadelerdir. Öykünün akışı içinde Bey'in lokantadan ayrılması ile lokanta sahibinin diğer müşterilerin yanına geri dönmesi arasındaki kısa süreyi ifade eden هنيهة sözcügünü Doğru daha esnek bir ifadeyle aktarırken, Dağbaşı ve Demirayak geçen süreyi biraz daha netleştirerek çevirmişlerdir. Dağbaşı'nın metindeki مدة وجود الزائر الثالث في المطعم söz öbeğini, Doğru'nun ise غريبة sıfatını eksilttiği görülmektedir. Buna karşılık Demirayak'ın kendinden önceki يعتذر fiiline gönderme yapan ذلك olumsuz etkilemiştir. Bu kesitteki belki de en dikkat çekici farkl11ık لهجة kelimesinin çevirisinde görülmektedir. Her üç tercih de لهجة kelimesinin sözlük karşlıkları arasında mevcuttur. Dağbaşı bu sözcügü 'şive' olarak çevirmiştir. Ancak muhtemelen öyküde bu sözcükle kastedilen, Ebû Assâf'ın kelimeleri söyleyişinin değişmesinden ziyade, Bey'e duyduğu saygı ve korkudan kaynaklı sesinin kısık veya boğuk çıkması olabilir. Dolayısıyla telaffuzdan ziyade sesle ilgili bir durumdan bahsediliyor olması muhtemeldir. Demirayak'ın kullandığı 'telaffuz' kelimesi de yine konuşma esnasında kelimelerin söylenişiyle ilgilidir. Doğru'nun ise bu kelimeyi 'ses tonu' olarak hedef dile aktararak kaynak metinde verilmek istenen anlamı daha doğru bir biçimde yansıttığı söylenebilir.

\begin{tabular}{|l|l|}
\hline Nu'ayme (2000: 97) & \multicolumn{1}{|c|}{} \\
\hline Dağbaşı (2017: 153) & Bölgemizin mutlak hakimleriydiler \\
\hline Doğru (2002: 103) & Onlar dediğim dedik, astığım astık diyen kimselerdi. \\
\hline Demirayak (2000: 81) & İstedikleri gibi davranırlardı \\
\hline
\end{tabular}

Burada üç çevirmenin de birbirinden farklı tercihler yaptığını görülmektedir. Çevirilere genel olarak bakıldığında çevirmenlerin 'mutlak irade' anlamını değişik yorumlarla yansıttığı göze 
çarpmaktadır. Her üç çeviri de verilmek istenen anlamı doğru olarak aktarılmıştır. Dağbaşı'nın, çevirisinde diğer çevirmenlere nazaran kaynak metne daha sadık kaldığı görülür. Bölge kelimesini çeviriye ekleyerek bahsedilen kişilerin söz sahibi olduğu yeri nitelemiş ve bununla, önceki cümlede bahsedilen Lübnan'a gönderme yapmıştır. Ayrıca o bölgenin anlatıcının memleketi olması sebebiyle kelimenin sonuna birinci çoğul iyelik eki eklemiştir. Doğru, çevirisinde bölgenin hakimiyetinden مطلقي ئ ziyade, bölgeye hakim olanların zalimliğini vurgulayan bir deyim kullanmıştır. Demirayak ise ifadesini doğrudan çevirmek yerine onunla kastedilen anlamı aktaran bir yorumlamaya gitmiş ve kaynak metinde bulunmayan 'davranmak' fiilini çevirisine eklemiştir.

\begin{tabular}{|c|c|}
\hline Nu'ayme (2000: 97) & فجار الدهر عليهم بعد حين كما جار على الكثير من الأمر اءو المشايخ سواهم. \\
\hline Dağbaşı (2017: 153) & $\begin{array}{l}\text { Bir süre sonra birçok prense, şeyhe ve diğerlerine yaptı̆̆ı gibi zaman onları } \\
\text { da yok etti. }\end{array}$ \\
\hline Doğru (2002: 103) & $\begin{array}{l}\text { Sonra felek başka pek çok lideri ve yöneticiyi olduğu gibi onları da kasıp } \\
\text { kavurdu. }\end{array}$ \\
\hline Demirayak (2000: 81) & $\begin{array}{l}\text { Bir süre sonra felek, başka birçok prens ve şeyhe vurduğu gibi onlara da } \\
\text { tokadını vurdu. }\end{array}$ \\
\hline
\end{tabular}

Kaynak metin cümlesinin hemen başında karşımıza çıkan deyimin çevirisi için üç çevirmenin de farklı tercihler yaptığını görmekteyiz. Her üç çeviri de anlamsal olarak doğrudur. Dağbaşı deyimi hedef dile aktarırken kaynak metinden dışarı çıkmayarak öykünme yönteminden faydalanmıştır. Doğru ve Demirayak ise kültürel ögeleri dikkate alarak deyimin hedef dildeki eşdeğerini bulmaya odaklanmışlar. Demirayak çevirisininde hedef dildeki tam eşdeğeri kullanırken, Doğru'nun çevirisi Türkçedeki iki farklı deyimi harmanlayan bir cümle olmuştur. Ayrıca Doğru kaynak metindeki الأمراء والمشايخ sözcüklerini kaydırarak hedef dile daha yakın ve daha serbest bir çeviriyi benimsemiştir. Dağbaşı ve Demirayak'ın ise seçimlerinde kaynak metne yakın durdukları söylenebilir.

\begin{tabular}{|l|l|}
\hline Nu'ayme (2000: 98) & \multicolumn{1}{|l|}{$\quad$ الموت ولا الصبر على هذه الإهانةً! } \\
\hline Dağbaş1 (2017: 153) & Ölüm bile bu durumdan daha iyiydi. \\
\hline Doğru (2002: 104) & Ölünür ama sabredilmez bu alçaklığa! \\
\hline Demirayak (2000: 82) & Bu ihanet karşısında sabretmektense ölmek yeğ idi. \\
\hline
\end{tabular}

Burada üç çevirmenin de farklı tercihler yaptığını görmekteyiz. Çevirilere baktığımızda هان sözcügünün aktarımı için tercih edilen farklı kelimeler dikkati çekmektedir. Arapça ve Türkçe arasında çağlar boyunca var olan kültürel ve tarihi etkileşimler bu iki dil arasında ödünçleme yoluyla kelime alışverişi yaşanmasına sebep olmuştur. Bir kelimenin anlamsal olarak bir değişikliğe uğramadan diğer dilde kullanılması durumunda bu sözcük çeviri literatüründe 'gerçek dostlar' terimiyle adlandırılır. Bunun aksi olarak iki dilde de var olan ancak farklı anlamlarda kullanılan sözcükler ise 'sahte dostlar' dır. Buradaki إ إنانة kelimesinin anlamı Arapçada hakaret, küçük düşürme, saygısızlık anlamında kullanılırken Türkçede anlam kaymasına uğrayarak hainlik, arkadan vurma, aldatma gibi anlamlarda kullanılmaktadır. Demirayak çevirisinde هإنة kelimesinin Arapçada kullanıldığı durumu göz ardı ederek kelimeyi Türkçede farklı bir anlama gelen ihanet kelimesiyle karşılamıştır. Dağbaşı ise kelimeyi direkt olarak çevirmemiş, onunla kastedilen duruma gönderme yaparak daha genel bir ifade kullanmıştır. Ayrıca sözcük düzeyinde bir çeviri yapmak yerine bu durumu Türkçede ifade eden bir deyim kullanmıştır. Doğru ise hem sözcük hem anlam düzeyinde kaynak metne sadık kalmış, ayrıca diğer çevirmenlerden farklı olarak kaynak metindeki öfkeli vurguyu hedef metinde de aynı şekilde korumuştur. 


\begin{tabular}{|c|c|}
\hline Nu'ayme (2000: 99) & ثم هبّو ا كرجل و احد و اقفين. و هكذا وققو ا بضع دقائق كأصنام دون أن يحرك أحدهم شفه. \\
\hline Dağbaşı (2017: 154) & $\begin{array}{l}\text { Sonra tek vücut gibi şeyhin etrafını sardılar, kıllarını bile kıpırdatmadan } \\
\text { birkaç dakika put gibi durdular. }\end{array}$ \\
\hline Doğru (2002:105) & $\begin{array}{l}\text { Sonra tek bir kişi gibi hep birden ayağa firladılar. Birkaç dakika dudaklarını } \\
\text { bile kıpırdatmadan öylece putlar gibi dikili kaldılar. }\end{array}$ \\
\hline Demirayak (2000:83) & $\begin{array}{l}\text { Sonra hepsi birden ayağa kalktılar, hiçbiri dudağını kıpırdatmadan, putlar } \\
\text { gibi öylece kaldılar bir süre. }\end{array}$ \\
\hline
\end{tabular}

Her üç çevirmen de كرجل و واحد söz öbeğini farklı şekillerde çevirmiştir. Dağbaş1 'tek vücut gibi', Doğru 'tek bir kişi gibi', Demirayak 'hepsi birden' ifadelerini tercih etmiştir. Dağbaşı deyimin Türkçedeki karşılığını kullanırken, Doğru kaynak metne sadık kalmıştır. Demirayak ise anlama odaklanmış ve deyimin karşılığı olan 'birlikte hareket etmek' ifadesini yansıtan bir çeviri yapmıştır. Ayrıca Dağbaşı'nın 'هَّ fiilini kaydırarak 'etrafını sardılar' şeklinde çevirdiği görülmektedir. Demirayak kaynak metne sadık kalırken Doğru, verilmek istenen 'panik halinde ve aceleyle ayağa kalkma' anlamını güçlendirerek hedef dile aktarmıştır. Kaynak metindeki diğer bir deyim olan دون söz öbeği, Demirayak ve Doğru tarafindan kaynak metin odaklı yöntemle sözcüğ̈̈ sözcügüne karşılıkları verilerek çevrilmiştir. Dağbaşı ise hedef dildeki eşdeğeri bulmaya odaklanmıştır.

\begin{tabular}{|c|c|}
\hline Nu'ayme (2000: 99) & الصليب على وجهه: \\
\hline Dağbaşı (2017: 154) & $\begin{array}{l}\text { Her tarafı büyük bir korku sarmıştı. Sonunda kâhin cesaretini topladı, } \\
\text { istavroz çıkardıktan sonra titrek bir sesle şöyle dedi: }\end{array}$ \\
\hline Doğru (2002: 105) & $\begin{array}{l}\text { Ödleri kopmuştu. Sonra rahip cesaretini topladı ve yüzüne haç işareti } \\
\text { çizdikten sonra titrek bir sesle: }\end{array}$ \\
\hline Demirayak (2000: 83) & $\begin{array}{l}\text { Korku sarmışı bütün benliklerini. Sonunda rahip cesarete geldi ve istavroz } \\
\text { çıkardıktan sonra ürkek bir sesle: }\end{array}$ \\
\hline
\end{tabular}

Her üç çevirmen de bu kesitin ilk cümlesini olușturan deyimi hedef odaklı bir yaklaşımla farklı şekillerde aktarmıştır. Üç çeviri de öyküde bahsedilen grubun duyduğu korkuyu yansıtmaktadır. Dağbaşı ve Demirayak'ın çevirileri birbirine daha yakın dururken Doğru, deyimin hedef dildeki eşdeğerini kullanmış ve yaptığı çeviriyle duyulan korkunun şiddetini okuyucuya daha fazla hissettirmiştir. Ayrıca metindeki كاهن sözcügüü de iki farklı şekilde çevrilmiştir. Dağbaşı hedef dilde de var olan bu sözcüğü değiştirmeden aktarırken, Doğru ve Demirayak bunu 'rahip' sözcüğüyle karşılamışlardır. Kaynak metinde كاهن kelimesiyle kendisinden bahsedilen kişi kilisenin görevlisi olan bir din adamıdır. Dolayısıyla bu kelimenin Türkçede 'rahip' veya 'papaz' olarak karşılanması, anlamı hedef dil okuyucusuna doğru aktarmak için daha uygun olabilir. Zira 'kahin' kelimesi hedef dilde gelecekten haber veren kimse olarak kullanılır ve sadece Hristiyanlığa özgü bir kavram değildir. Diğer bir dikkat çekici tercih de رسم علامة الصليب على وجها söz öbeğinin aktarımında görülür. Doğru bu söz öbeğini kaynak metne tamamen bağlı kalarak sözcüğü sözcüğüne aktarmıștır. Doğru'nun bu tercihin sebebi, 'istavroz çıkarmak' kavramının bazı okuyucular tarafından bilinmiyor olabileceği düşüncesinden kaynaklanan bir anlaşılmama kaygısı olabilir. Dağbaşı ve Demirayak ise bu ifadenin çevirisinde hedef dildeki eşdeğere odaklanmışlardır. 


\begin{tabular}{|c|c|}
\hline Nu'ayme (2000: 99-100) & فقامت البلدة تحرق ما عندها من البترول و الهثيم، وقام الدبك" ودار التهليل "يا بيكنا!" \\
\hline Dağbaşı (2017:154) & $\begin{array}{l}\text { Kutlamalar yapıldı, ateşler yakıldı, yöresel oyunlar oynandı, halk "Beyimiz, } \\
\text { Beyimiz" diye bağırdı durdu. }\end{array}$ \\
\hline Doğru (2002:106) & $\begin{array}{l}\text { Yöre halkı, elinde bulunan petrol ve samanları yaktı. Halaylar çekildi, } \\
\text { oyunlar oynandı. "Beyimiz, Beyefendimiz" çığlıkları ortalığı sardı. }\end{array}$ \\
\hline Demirayak (2000: 83) & $\begin{array}{l}\text { Belde halkı gaz yağı ve otlardan ateşler yaktı, halaylar çekildi ve "Beyimiz } \\
\text { çok yaşa" naraları atıldı. }\end{array}$ \\
\hline
\end{tabular}

Dağbaşı diğer çevirmenlere göre hedef dile daha yakın durarak ekleme ve eksiltmelerin olduğu bir çeviriyi tercih etmiştir. Kaynak metindeki تحرق ما عندها من البترول والهشيم söz öbeğiyle kastedilen anlamı açımlama yaparak aktarmıştır. Doğru ve Demirayak'ın tercihlerinin ise kaynak odaklı olduğunu görmekteyiz. Dağbaşı'nın eksilttiğgi البترول و الهشيم sözcüklerini Doğru, olduğu gibi aktarırken, Demirayak البترول sözcüğünü 'gaz yağı' olarak kaydırmıştır. Bunun sebebi de halkın elinde petrolden ziyade gaz yağı bulunduğunu düşünmesi olabilir. Ayrıca kaynak metinde halkın eğlencede oynadıkları bir oyun türü olan "الدبك nin Arap kültürüne özgü olduğunu belirtmek için Dağbaş1 'yöresel' sözcüğünü çevirisine eklemiştir. Doğru ve Demirayak ise "الدبك" kelimesini yerlileştirerek Türk kültüründeki eşdeğeri olan halay sözcüğüyle karşılamışlardır. Son olarak Demirayak'1n "يا بيكنا! ünlemini daha serbest bir çeviri yaklaşımı benimseyerek aktarıp hedef metinde oluşturduğu cümleye 'çok yaşa' eklemesinde bulunması, Türkçedeki yaygın kullanıma uygun olmuştur.

\begin{tabular}{|c|c|}
\hline Nu'ayme (2000: 100) & 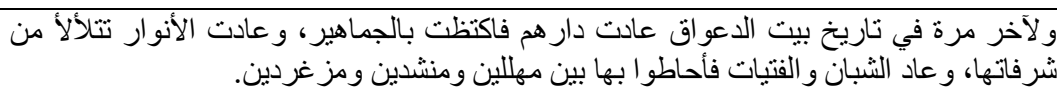 \\
\hline Dağbaşı (2017: 154) & $\begin{array}{l}\text { ed-Da'vâk ailesi tarihinde bir kez daha evleri göstericilerle doldu taştı, } \\
\text { 1şıklar parlıyordu, gençler şarkılar söyleyerek, zılgitlar çekerek evin etrafinı } \\
\text { sarmıştı. }\end{array}$ \\
\hline Doğru (2002: 106) & $\begin{array}{l}\text { Davak ailesinin tarihinde uzun bir süreden beri ilk kez evleri yeniden } \\
\text { insanlarla dolup taştı ve yeniden balkonlarından 1şıklar parıldadı. } \\
\text { Delikanlılar ve genç kızlar gelip çı̆glıklar, şarkılar ve zılgıtlar arasında orayı } \\
\text { kuşattılar. }\end{array}$ \\
\hline Demirayak (2000: 83) & $\begin{array}{l}\text { ed-Da'vâk ailesinin tarihinde son kez evleri kalabalık misafirlerle dolup } \\
\text { taştı, balkonlarından 1ş1klar tekrar yayıldı, delikanlı kızlar ve oğlanlar } \\
\text { ilahiler, marşlar ve şarkılar söyleyerek gelip evi kuşattılar. }\end{array}$ \\
\hline
\end{tabular}

Çevirilere baktığımızda çevirmenlerin kaynak metindeki anlama bağlı kalmakla beraber birbirlerinden oldukça farklı tercihler yaptıkları görülmektedir. Burada öncelikle dikkati çeken kaynak metnin ilk kelimesi olan لآخر مرة ifadesinin aktarımıdır. Demirayak kaynak metne sadık kalarak çevirisini yaparken Doğru ve Dağbaşı'nın daha serbest bir çeviri yaptığı görülmektedir. Doğru 'son kez' anlamındaki bu tamlamayı ilk kez olarak kaydırmıştır. Ayrıca cümleye 'uzun bir süreden beri' eklemesinde bulunmuştur. Dağbaşı ise 'bir kez daha' şeklinde bir aktarımı tercih etmiştir. Çevirmenlerin diğer bir farklı tercihini de جماهير kelimesinin aktarımında görüyoruz. Kelimeyi Dağbaşı 'göstericiler', Doğru 'insanlar', Demirayak 'kalabalık misafirler' olarak kaydırmıştır. Kutlamalara katılan bölge halkının kastedildiği bu kelimenin anlamını her üç çevirinin de herhangi bir anlam kaybı olmadan yansıttığını söyleyebiliriz. Dağbaş1 الثبان والفتيات sözcüklerini genelleştirerek tek bir sözcük olarak hedef dile aktarmıştır. Doğru ise hem kaynak metne bağlı hem de hedef dil kullanımına uygun ifadelerle çevirisini yapmıştır. Demirayak çevirisinde sözcüklerinin sıralamasını değiştirmiştir. Ayrıca tercih ettiği 'delikanlı kızlar' ifadesi hedef dil kullanımına uygun değildir. Delikanlı kelimesi Türkçede genç erkekler için kullanılan bir ifadedir. Demirayak'ın مهزلين sözcüklerinin çevirisi için tercih ettiği 'ilahi' ve 'marş' karş1lıkları, kaynak metindeki halkın çoşkulu kutlama ortamını yansıtmak için uygun olmamıştır. Daha ziyade, çeviriye kaynak metinde betimlenen ortamdan farklı olarak resmi bir kutlama töreni havası katmıştır. Dağbaşı ve Doğru'nun çeviri tercihlerinin kaynak metindeki bu çoşkuyu hedef dile aktardığı söylenebilir. 
Ayrıca Doğru diğer çevirmenlerden farklı olarak kaynak metin cümlesini hedef metne iki cümle biçiminde aktarmıştır.

\begin{tabular}{|c|c|}
\hline Nu'ayme (2000: 102) & 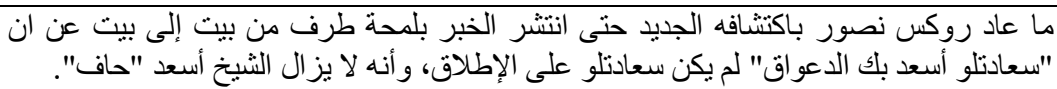 \\
\hline Dağbaşı (2017:155) & $\begin{array}{l}\text { Ravkas Nasûr döner dönmez haber göz açıp kapanıncaya kadar evden eve } \\
\text { yayıldı, Es'ad Bey Hazretlerinin kesinlikle "Bey Hazretleri” olmadığı, hala } \\
\text { Şeyh Es'ad olduğu ortaya çıktı. }\end{array}$ \\
\hline Doğru (2002: 108) & $\begin{array}{l}\text { Ravkes Nasur bu yeni bilgiyle döner dönmez, Esad Davak Beyefendi'nin } \\
\text { aslında bir beyefendi olmadığı ve hala o baldırı çıplak SSeyh Esat olduğu } \\
\text { haberi evden eve göz açıp kapayıncaya kadar yayıllıerdi. }\end{array}$ \\
\hline Demirayak (2000:85) & $\begin{array}{l}\text { Roks Nassûr bu yeni keşfiyle döner dönmez "Es'ad Bey ed-Da'vâk } \\
\text { Hazretleri"nin kesinlikle "Hazretleri”" olmadığı ve hala "Muhtar Es'ad Hâf" } \\
\text { olduğu haberi bir anda evden eve yayıldı. }\end{array}$ \\
\hline
\end{tabular}

Çevirilere bakıldığında çevirmenlerin metindeki özel ismin hedef dile aktarımı için tercih ettikleri farklı transkripsiyon seçimleri göze çarpmaktadır. Ayrıca Sayın ..., ... Bey gibi saygı ifade etmek için kullanılan سعادتلو kelimesinin çevirisi için Dağbaşı ve Demirayak saygıyı ve hürmeti daha yoğun hissettiren 'Bey Hazretleri' ifadesini kullanırken, Doğru 'Beyefendi' şeklinde bir aktarımı tercih etmiştir. Dağbaş1 ve Doğru olayın aniden bir anda olduğunu ifade eden بلمحة kelimesini sözcügü sözcügüne çevirmek yerine hedef odaklı bir yaklaşımla kültürel öğeleri de dikkate alarak durumu daha güzel ifade eden Türkçedeki deyimi kullanmıştır. Demirayak ise bu kelime için sözcüksel düzeyde bir çeviri yaklaşımını tercih etmiştir.

انتشر من بيت Her üç çevirmen de kaynak metinde geçen 'evden eve yayılmak' anlamındaki deyimini hedef dilde de kullanılması sebebiyle aynı şekilde çevirmiştir. Doğru diğer çevirmenlerden farklı olarak 'yayıldı' yerine 'yayılıverdi' fiilini kullanmıştır. Ancak burada verilmek istenen tezlik anlamını zaten hemen öncesinde geçen 'göz açıp kapayıncaya kadar' deyimi yeterince ifade etmektedir. Doğru ve Dağbaşı kaynak metinde geçen شيخ kelimesini değiştirmeden hedef dile aktarmışlardır. Bu kelime kaynak metinde bir bölgenin veya aşiretin lideri anlamında kullanılmıştır. Ancak Türkçede 'şeyh' kelimesi Müslümanlığa özgü bir kelimedir ve dini lider anlamında kullanılmaktadır. Bu da hedef dil okuyucuların aklını karıştırarak öykünün kahramanı Esad Davak'ın konumunun ve mensubu olduğu dinin yanlış anlaşılmasına neden olabilir. Demirayak'ın ise bu kelimeyi 'muhtar' olarak kaydırdığı görülmektedir. Kültürümüzde bu tarzda bir liderlik anlayışının olmaması sebebiyle her iki tercihin de kaynak metindeki anlamı tam olarak karşılamadığı söylenebilir.

Dağbaşı çevirisinde Esad Davak'1 niteleyen 'yalınayak' anlamındaki 'حاف sifatını eksiltmiş̧tir. Kelime kaynak metinde soyut anlamıyla kullanılmıştır ve kahramanın beş parasızlığını ve saygınlığını yitirdiğini ifade etmektedir. Doğru, bu kelimeyi hedef dildeki eşdeğeri olan 'baldırı çıplak' deyimiyle karşılamıştır. Demirayak ise 'حاف' sanki hedef dilde karş1lığı bulunmayan bir kelimeymişçesine ödünçleme yöntemine başvurmuş ve kelimeyi çevirmek yerine Türkçe sesletime uygun biçimde hedef dile aktarmıştır.

\section{Sonuc}

Modern Arap edebiyatında kısa öykü türünün ilk örneklerini veren önemli isimler arasında yer alan Mîhâil Nua'yme'nin 1932 yılında kaleme aldığı Kâne mâ Kâne adlı öykü koleksiyonunun en güzel öykülerinden biri olan Saâdetu'l-Beyk'in, Erdinç Doğru, Gürkan Dağbaşı ve Kenan Demirayak tarafindan dilimize kazandırılan çevirileri, karşılaştırmalı çözümleme yöntemi ile incelenmiştir. Kaynak ve hedef metinlerden seçtiğimiz kesitlerin incelenmesi sonucunda çevirmenlerin tercihleri ve yakın oldukları çeviri yaklaşımları hakkında birtakım çıkarımlara varılmıştır. 
Üç çevirinin bütünü incelendiğinde çevirmenlerin genel olarak anlamsal eşdeğerliği sağladıklarını görülmektedir. Tabi bunu kendi amaçları doğrultusunda farklı tercihlerle gerçekleştirmişlerdir. Çevirmen tercihleri arasındaki farklar yoğun olarak deyimlerin aktarımında kendini göstermiş̧tir. Her üç çevirmen de deyimlerin aktarımında çoğunlukla hedef dildeki eşdeğeri bulmaya odaklanmışlardır. Çevirmenler bazen kaynak metin bazen hedef metin kültürüne yakın bir çeviri tercih etmiştir. Ancak ağırlıklı olarak tercih ettikleri yaklaşımlara bakarak şunları söyleyebiliriz:

Dağbaşı'nın daha serbest bir çeviriyi benimsediği, sade ve öz bir çeviriye ulaşmak için zaman zaman eksiltmelere başvurarak Türkçede yalın bir dil oluşturmayı hedeflediği söylenebilir. Demirayak ise her ne kadar bazı durumlarda özellikle de deyimlerin çevirisinde hedef kültüre yakın durmayı tercih etse de çoğunlukla tercihlerini kaynak metne sadakat yönlendirmiştir. Dolayısıyla bazı durumlarda hedef kültürde pek de kabul görmeyen ifadeleri çevirisinde kullanmıştır. Doğru ise kaynak metindeki hemen hemen hiçbir ifadeyi eksiltmemiş, aynı zamanda da hedef kültür normlarına uygun çeviriler yaparak hem kaynak metinden taviz vermemiş hem de hedef kültürü göz ardı etmeden çevirisini yapmıştır. Son olarak çevirmenlerin bazen yeterli bazen de kabul edilebilir bir çeviri oluşturmayı hedefledikleri söylenebilir. Ancak ağırlıklı olarak tercih ettikleri yaklaşımlara baktığımızda, Dağbaşı ve Doğru'nun kabul edilebilir bir çeviri metni oluşturmaya çabaladığı görülürken; Demirayak daha çok kaynak dil ve kültür odaklı sadık bir yaklaşımla yeterli bir çeviri metni ortaya koymuştur.

\section{Kaynakça}

Aksoy, B. (2001). Çeviride çevirmen seçimleri 1şığında çeviri eleştirisi. Hacettepe Üniversitesi Edebiyat Fakültesi Dergisi, 18(12), 1-16.

Aksoy, B. (2002). Geçmişten günümüze yazın çevirisi. İmge Kitabevi.

Aktaş, T. (1996). Çeviri işlemine genel bir bakış. Orsen Matbaaacılık.

Bengi, I. (1993). Çeviri eleştirisi bağlamında eleştirel bilincin oluşması ve eleştiri, üst-eleştiri, çeviribilim ilişkileri. Dilbilim Araştırmaları Dergisi, (4), 25-50.

Broeck, R. Van den. (1985). The manipulation of literature: Studies in literary translation. Croom Helm.

Çetişli, İ. (2009). Çağdaş Mısır Öyküsü I. Hece Öykü Dergisi. 6(31), 55-128.

Dağbaşı, G. (2017). Muhammed Teymûr'un Fî’'l-Kitâr isimli kısa öyküsünün farklı çevirilerinin karşılaştırmalı olarak değerlendirilmesi. Hitit Üniversitesi Sosyal Bilimler Enstitüsü Dergisi, 10(2), 1409-1424. https://doi.org/10.17218/hititsosbil.296620

Demirayak, K. (2000). Kisır. Babil Yayınları.

Demirci, G. (2014). Mısır edebiyatında kısa hikâye [Yüksek lisans tezi]. Atatürk Üniversitesi Sosyal Bilimler Enstitüsü.

Doğru, E. (2002). Onuncu günde kaplanlar. Meneviş Yayınları.

Ece, A. (2008). "Çeviri eleştirisinde yaklaşımlar.” Çeviri seçkisi I: Çeviriyi düşünenler. Ed. M. Rifat.: Sel Yayıncilık. 137-147.

Emekli, İ. (2006). Abdurrahman Munîf, hayatı, edebi kişiliği ve en-Nihâyât adlı romanının incelenmesi [Yayımlanmamış yüksek lisans tezi]. Atatürk Üniversitesi Sosyal Bilimler Enstitüsü.

Göktürk, A. (1994). Çeviri: Dillerin dili. Yapı Kredi Yayınları. 
Gürçağlar, T. Ş. (2011). Çevirinin ABC'si. Say Yayınları.

Hafız, S. (2003). Modern Arap kısa öyküsü (I). (A. Yüksel, Çev.). Nüsha Dergisi, 3(9), 1-25.

Hamidov, M. (2015). Edebiyat eleştirmeni olarak Mîhâîl Nu ayme. 185-199.

Karantay, S. (1987). Çeviri eleştirisi: Sorunlar, ilkeler, uygulamalar. Metis Çeviri Güz, 1, 49-56.

Koç, C. T. (2013). Mihail Nuayme; "Bey'in "Saadet"i. Mahalle Mektebi Edebiyat Dergisi, 2(9), 5053.

Mekkî, T. A. (1999). el-Kıssatu'l-kasiyra. Daru'l Mearif.

Newmark, P. (1988a). Approaches to translation. Prentice Hall.

Newmark, P. (1988b). A textbook of translation. Prentice Hall International.

Nu'ayme, M. (2000). Kâne mâ kâne. Dâru'l- Nûfel.

Paker, S. (1983). Çeviride 'yanlış/doğru' sorunu ve şiir çevirisinin değerlendirilmesi. Yazko Çeviri, $13,131-139$.

Paker, S. (1988). Çeviri eleştirisinin kuramla ilişkisi üzerine bazı düşünceler. Metis Çeviri, 4, 116121.

Polat, İ. E. (2018). Başka dilde yaşamak: Arap dilinde yaşayan Türkçe kelime ve yapılar. Dil Araştırmaları Dergisi, 0(22), 119-133.

Rifat, M. (2008). Çeviri seçkisi I: Çeviriyi düşünenler. Sel Yayıncılık.

Suçin, M. H. (1998). Yahyâ Hakkî ve Kısasuhâ el-Kasîra [Yayımlanmamış yüksek lisans tezi]. Gazi Üniversitesi Sosyal Bilimler Enstitüsü.

Suçin, M. H. (2013). Öteki dilde var olmak. Say Yayınları.

Tanrıkulu, L. (2018). Behçet Necatigil'in Thomas Mann'dan yaptı̆̆ 1 "Venedik'te Ölüm" çevirisinin çağdaş çeviri eleştirisi yaklaşımları açısından değerlendirilmesi. Firat Üniversitesi Sosyal Bilimler Dergisi, 28(1), 37-46. https://doi.org/10.18069/firatsbed.388061

Tasa, M. (2006). Suriye öykücülerinden Mâcid Reşîd el-'Uveyyid'in “Sıcak Bir Yaz”1. Marife Dini Araştırmalar Dergisi, 6(2), 133-150.

Tekalp, S. (2017). James Joyce'un “The Sisters” adlı kısa hikâyesinin Türkçe çevirilerinde kültürel unsurlar ve çeviri stratejileri. Batman Üniversitesi Yaşam Bilimleri Dergisi, 7(2/1), 182-191.

Türkan, İ. (2011). Mîhâîl Nu'ayme ve öykücülüğü. [Yüksek lisans tezi]. Selçuk Üniversitesi Sosyal Bilimler Enstitüsü.

Uluşahin, Ş. E. (2018). Serdar Özkan'ın Kayıp Gül adlı yapıtındaki gül teşbihinin Fransızca çevirisi La Rose Retrovee'de karş1laştırmalı incelemesi, Cumhuriyet Üniversitesi Edebiyat Fakültesi Sosyal Bilimler Dergisi, 42(2), 145-161.

Ünsal, G. (2017). Çeviri eleştirisi açısından çeviri metin inceleme çalışması. Avrasya Sosyal ve Ekonomi Araştırmaları Dergisi, 4(11), 243-253.

Yalçın, P. (2003). Vedat Gülşen Üretürk’ün Kırmızı ve Siyah çevirisindeki dil kullanımı. Dil Dergisi, 12 (118), 34-42.

Yıldız, M. (2002). Arap edebiyatında ilk modern kısa öykü: Muhammed Teymûr'un Fi'1Kıtâr'1. Nüsha Şarkiyât Araştırmaları Dergisi, 2(4), 43-55.

Yıldız, M., \& Özcan, M. (2017). Türkçe çevirileriyle Arapça kısa öyküler. Akdem Yayınları. 
Yıldız, M., \& Şanverdi, H. İ. (2019). Azrâ'u Câkartâ adlı romanın Türkçe çevirilerinin çeviri stratejileri açısından incelenmesi. Dil ve Edebiyat Araştırmaları Dergisi, 19(19), 237-262. https://doi.org/10.30767/diledeara.542608

Yıldız, Ş. (2004). Çeviride eşdeğerlik ve çeviri kuramları bağlamında karşılaştırmalı bir çalışma. Selçuk Üniversitesi Sosyal Bilimler Enstitüsü Dergisi, (12), 375-386.

Yücel, F. (2007). Çeviri eleştirisi neyi eleştirir?. Uludă̆ Üniversitesi Fen-Edebiyat Fakültesi Sosyal Bilimler Dergisi, 8(12), 39-58. 